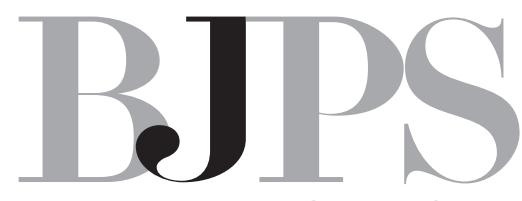

\title{
The importance of B cells in the development of preventive and therapeutical approaches against Dengue, Zika and Chikungunya viral infections
}

Among the deadliest animals on the planet, mosquitoes occupy the number 1 in the ranking. They are capable of transmitting several diseases caused by parasitic, bacterial or viral pathogens. The prevalence of mosquito borne-diseases is higher in tropical areas where high humidity and temperature as well as unplanned urbanization are found. In the context of viral diseases, a particular mosquito vector, Aedes aegypti, has been in the spotlight. It transmits Yellow Fever (YFV), Dengue (DENV), Zika (ZIKV) (all Flaviviruses) and Chikungunya (CHIKV) viruses (alphavirus) to humans. Recently, DENV, ZIKV and CHIKV infection outbreaks have been detected simultaneously in the same locations, such as French Polynesia (Musso et al., 2015) or Brazil (Brazilian Ministry of Health, 2016 -http://portalsaude.saude.gov.br/images/pdf/2016/ maio/17/2016-016---Dengue-SE16-publica----o.pdf), raising global concerns. There is evidence that ZIKV transmission occurs through mosquito bite, blood or sexual contact (Foy et al., 2011; Musso et al., 2015; McCarthy, 2016). Generally, its symptoms are mild and similar to DENV and CHIKV infections. Nevertheless, some ZIKV-infected patients showed development of neurological alterations such as Guillain-Barré syndrome (Brasil et al., 2016), microcephaly, macula atrophy and others (Li et al., 2016; Mlakar et al., 2016; Ventura et al., 2016; Cugola et al., 2016; Garcez et al., 2016). Currently, Brazil is a major hotspot for DENV, ZIKV and CHIKV infections, which have been detected in almost all regions of the country (Cardoso et al., 2016). Unfortunately, Brazilians have struggled with government slow actions in response to those epidemics. Consequently, it delays their diagnostics and the start of a treatment, raising awareness that those viral infections may spread out quickly in the Americas and other parts of the world where Aedes mosquitoes reside.

Regarding the immune responses against those three viral infections, they usually induce antibodies with neutralizing abilities (Dejnirattisai et al., 2015; Clapham et al., 2016; Dai et al., 2016; Smith et al., 2015). However, DENV-specific responses are more complex because there are four different viral serotypes and the antibody response induced by one serotype does not protect against the other (reviewed by Whitehead et al., 2007). Instead of virus neutralization, the elicited process is antibody-dependent enhancement of infection (ADE) on Fc receptor-bearing cells (Dejnirattisai et al., 2010). Considering that ZIKV has about $43 \%$ identity with the DENV polyprotein or the envelope ectodomain (Lazear, Diamond, 2016), it requests further analyses whether ZIKV-specific antibodies derived from a previous infection can induce DENV ADE. Apparently, DENV-specific antibodies not only bind ZIKV, but also trigger ZIKV ADE (Cardoso et al., 2015). Interestingly, most of the confirmed ZIKV infection cases in the Brazilian Northeast states were of DENV-exposed individuals. 


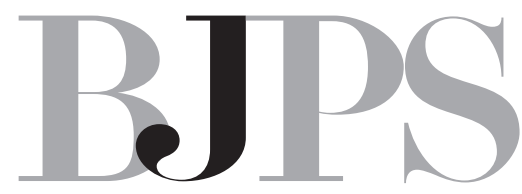

Brazilian Journal of

Pharmaceutical Sciences

In terms of antibody-secreting cell responses, there is a massive antigen-specific plasmablast response during the acute phase of DENV infection, accounting for more than $50 \%$ of all IgG-secreting cells (Wrammert et al., 2012; Garcia-Bates et al., 2013). Similarly, an Asian ZIKV strain elicited an increased plasmablast frequency seven days after challenge in rhesus macaques. However, that evaluation did not verify what percentage of cells was antigen-specific (Dudley et al., 2016). On the other hand, there is not much data available about the plasmablast response in the context of CHIKV infection, but only antibody titers and their neutralisation capacities in the serum (Yoon et al., 2015).

Although the YFV-specific vaccine (YF-17D strain) is one of the most effective formulations developed so far, there are no protective vaccines against the other viruses transmitted by Aedes aegypti. Recombinant YF-17D constructs containing genes from different pathogens have been able to elicit substantial degrees of protection (Tao et al., 2005; Guy et al., 2010; Nogueira et al., 2011). DENV-specific YF-17D vectors were already made (Guy et al., 2010, 2011) and recently tested in clinical trials (Capeding et al., 2014; Villar et al., 2015). That type of recombinant construct greatly stimulates $\mathrm{T}$ cell and humoral responses (Monath et al., 2003; reviewed by Guy et al., 2010). Considering the pivotal role of antibodies in preventing viral infections post-vaccination as well as therapeutic tools (Caskey et al., 2015; Fibriansah, Lok, 2016; Pal et al., 2013), it is crucial that any vaccine candidates for DENV, ZIKV and CHIKV infections are able to promote extensive $\mathrm{B}$ cell responses. To study vaccine- or viral infection-derived B cell responses, different cell subsets could be assessed, such as memory B cells or plasmablasts. Although both cell types have been successfully used to produce antigen-specific monoclonal antibodies (mAbs) with neutralizing abilities, plasmablasts at the peak of response represent a more accessible source of material to produce antigen-specific mAbs (reviewed by Silveira et al., 2015). The knowledge of vaccine- or viral infection-derived mAb repertoire and their functional characteristics would certainly improve the development of preventive and therapeutic approaches against DENV (Silveira, 2015), ZIKV or CHIKV infections.

\section{ACKNOWLEDGEMENTS}

The author is indebted to Dr. Irene S. Soares (University of São Paulo) and Dr. Alexandre-BruniCardoso (University of São Paulo) for providing critical reading of this Editorial.

Eduardo L. V. Silveira

Department of Clinical and Toxicological Analyses, Faculty of Pharmaceutical Sciences, University of São Paulo 


\section{REFERENCES}

BRASIL, P. et al. Guillain-Barré syndrome associated with Zika virus infection. Lancet, v.387, p. 1482, 2016.

CAPEDING, M.R. et al. CYD14 Study Group. Clinical efficacy and safety of a novel tetravalent dengue vaccine in healthy children in Asia: a phase 3, randomised, observer-masked, placebo-controlled trial. Lancet, v.384, p.1358-1365, 2014.

CARDOSO C. W. et al. Outbreak of exanthematous illness associated with zika, chikungunya, and dengue viruses, Salvador, Brazil. Emerg Infect Dis., v.21, n.12, p. 2274-2276, 2015.

CASKEY, M. et al. Viraemia suppressed in HIV-1-infected humans by broadly neutralizing antibody 3BNC117. Nature, v.522, p.487-491, 2015.

CLAPHAM, H.E. et al. Dengue virus (DENV) neutralizing antibody kinetics in children after symptomatic primary and postprimary DENV infection. J. Infect. Dis., v.213, p.1428-1435, 2016.

CUGOLA, F.R. et al. The Brazilian Zika virus strain causes birth defects in experimental models. Nature., doi:10.1038/nature18296, 2016.

DAI, L. et al. Structures of the Zika virus envelope protein and its complex with a flavivirus broadly protective antibody. Cell Host Microbe, v.19, p.696-704, 2016.

DEJNIRATTISAI, W. et al. A new class of highly potent, broadly neutralizing antibodies isolated from viremic patients infected with dengue virus. Nat. Immunol., v.16, p.170-177, 2015.

DEJNIRATTISAI, W. et al. Cross-reacting antibodies enhance dengue virus infection in humans. Science, v. 328, p.745-748, 2010.

DUDLEY, D. et al. A rhesus macaque model of Asian lineage Zika virus infection. BioRxiv. http://dx.doi.org/10.1101/046334, 2016.

FIBRIANSAH, G.; LOK, S.M. The development of therapeutic antibodies against dengue virus. Antiviral Res., v.128, p.7-19, 2016.

FOY, B.D et al. Probable non-vector-borne transmission of Zika virus, Colorado, USA. Emerg. Infect. Dis., v.17, p. 880-882, 2011.

GARCEZ, P.P. et al. Zika virus impairs growth in human neurospheres and brain organoids. Science, v.352, p.816-818, 2016.

GARCIA-BATES, T.M. et al. Association between magnitude of the virus-specific plasmablast response and disease severity in dengue patients. J. Immunol., v.190, p.80-87, 2013.

GUY, B. et al. From research to phase III: preclinical, industrial and clinical development of the Sanofi Pasteur tetravalent dengue vaccine. Vaccine, v.29, p.7229-7241, 2011.

GUY, B. et al. Preclinical and clinical development of YFV 17D-based chimeric vaccines against dengue, West Nile and Japanese encephalitis viruses. Vaccine, v.28, p.632-649, 2010.

LAZEAR, H.M.; DIAMOND, M.S. Zika virus: new clinical syndromes and its emergence in the western hemisphere. J. Virol., 2016. In press. Available at: <http://jvi.asm.org/content/early/2016/03/03/JVI.00252-16.full.pdf+html>. Accessed on: March 19, 2016.

LI, C. et al. Zika virus disrupts neural progenitor development and leads to microcephaly in mice. Cell Stem Cell., v.19, p.1-7, 2016.

MCCARTHY, M. Zika virus was transmitted by sexual contact in Texas, health officials report. BMJ, v.352, i720, 2016. 
MLAKAR, J. et al. Zika virus associated with microcephaly. N. Engl. J. Med., v.374, p.951-958, 2016.

MONATH, T.P. et al. Chimeric live, attenuated vaccine against Japanese encephalitis (ChimeriVax-JE): phase 2 clinical trials for safety and immunogenicity, effect of vaccine dose and schedule, and memory response to challenge with inactivated Japanese encephalitis antigen. J. Infect. Dis., v.188, p.1213-1230, 2003.

MUSSO, D. et al. Potential sexual transmission of Zika virus. Emerg. Infect Dis., v.21, p.359-361, 2015.

MUSSO, D.; CAO-LORMEAU, V.M.; GUBLER, D.J. Zika virus: following the path of dengue and Chikungunya? Lancet, v. 386, p.243-244, 2015.

NOGUEIRA, R.T. et al. Biological and immunological characterization of recombinant yellow fever 17D viruses expressing a Trypanosoma cruzi amastigote surface protein-2 CD8+ T cell epitope at two distinct regions of the genome. Virol. J., v.8, p.127, 2011.

PAL, P. et al. Development of a highly protective combination monoclonal antibody therapy against Chikungunya virus. PLoS Pathog., v.9, p.e1003312, 2013.

SILVEIRA, E.L. et al. Vaccine-induced plasmablast responses in rhesus macaques: phenotypic characterization and a source for generating antigen-specific monoclonal antibodies. J. Immunol. Methods, v.416, p.69-83, 2015.

SILVEIRA, E.L.V. Dengue virus infection: current challenges and future perspectives. SM Vaccine Vaccin, v.1, p.1001, 2015.

SMITH, S.A. et al. Isolation and characterization of broad and ultrapotent human monoclonal antibodies with therapeutic activity against chikungunya virus. Cell Host Microbe, v.18, p.86-95, 2015.

TAO, D. et al. Yellow fever 17D as a vaccine vector for microbial CTL epitopes: protection in a rodent malaria model. J. Expl. Med., v.201, p.201-209, 2005.

VENTURA, C.V. et al. Zika virus in Brazil and macular atrophy in a child with microcephaly. Lancet, v.387, p.228, 2016.

VILLAR, L. et al. CYD15 Study Group. Efficacy of a tetravalent dengue vaccine in children in Latin America. N. Engl. J. Med., v.372, p.113-123, 2015.

WHITEHEAD, S.S. et al. Prospects for a dengue virus vaccine. Nat. Rev. Microbiol., v.5, p.518-528, 2007.

WRAMMERT, J. et al. Rapid and massive virus-specific plasmablast responses during acute dengue virus infection in humans. $J$. Virol., v.86, p.2911-2918, 2012.

YOON, I.K. et al. High rate of subclinical chikungunya virus infection and association of neutralizing antibody with protection in a prospective cohort in the Philippines. PLoS Negl. Trop. Dis., v.9, p.e0003764, 2015. 